\title{
Disruption of Retinogeniculate Pattern Formation by Inhibition of Soluble Guanylyl Cyclase
}

\author{
Catherine A. Leamey, Chrystal L. Ho-Pao, and Mriganka Sur \\ Department of Brain and Cognitive Sciences, Massachusetts Institute of Technology, Cambridge, Massachusetts 02139
}

During development of the visual system of the ferret, the terminals of retinal ganglion cell axons first segregate to form eye-specific layers and subsequently On-center and Off-center sublayers within the dorsal lateral geniculate nucleus (dLGN). Sublamination requires the activity of the afferent fibers, NMDA receptors, and nitric oxide synthase (NOS). We here report that soluble guanylyl cyclase (sGC), which in turn produces cGMP, is critically involved in the process of sublamination. cGMP expression is upregulated in both retinal terminals and postsynaptic dLGN cells during sublamination, and this expression is controlled by the activity of both NMDA receptors and NOS. Furthermore, the infusion of specific inhibitors of sGC or protein kinase $\mathrm{G}$ (PKG), a target of cGMP, prevents sublamination in vivo. We conclude that the SGC-CGMP-PKG pathway acts downstream of NMDA receptors and nitric oxide as an effector of the activity-dependent refinement of connections at this level of the mammalian visual system.

Key words: visual system development; ferret; lateral geniculate nucleus; activity; NMDA receptors; nitric oxide; soluble guanylyl cyclase; cGMP
The intracellular signals that regulate the activity-dependent development of connections in the mammalian brain are virtually unknown. The organization of the visual system in the ferret provides a good model for investigating possible mechanisms of developmental plasticity. At birth in this species, the axonal terminals of the retinal ganglion cells from the two eyes are intermixed in their principal target, the dorsal lateral geniculate nucleus (dLGN). Fibers from the ipsilateral and contralateral eyes first segregate to form eye-specific layers (Linden et al., 1981) during the first postnatal week. Later, during postnatal weeks $2-4$, the fibers segregate further within the eye-specific layers to form an inner sublayer (the On-sublamina) that receives terminals of On-center retinal ganglion cells and an outer sublayer (the Off-sublamina) that receives input from Off-center cells (Stryker and Zahs, 1983; Hahm et al., 1991). Sublamination is driven by activity from the retina, as the intraocular application of the sodium channel blocker tetrodotoxin disrupts this process (Cramer and Sur, 1997a). Postsynaptic activity also plays an important role, as the blockade of NMDA receptors in the dLGN prevents segregation of the presynaptic axons into sublaminas (Hahm et al., 1991, 1999). The participation of postsynaptic structures in what is essentially a presynaptic process of pattern formation suggests that a retrograde messenger is involved. Nitric oxide (NO) is likely to be such a messenger. NO synthase (NOS) is present in dLGN cells during development (Cramer et al., 1995;

Received Oct. 16, 2000; revised Feb. 27, 2001; accepted March 6, 2001.

This work was supported by a National Research Service Award postdoctoral fellowship (C.L.H.-P.) and National Institutes of Health Grant EY11512 (M.S.). We thank Jan de Vente for the generous gift of the cGMP antibody, Tara McHugh for technical assistance, and Jong-On Hahm for assistance with the HRP deposits. We also thank Drs. Richard Mark, Lauren Marotte, John Mitrofanis, Jeremy Taylor, Elly Nedivi, and Atomu Sawatari for their comments on previous versions of this manuscript.

Correspondence should be addressed to Dr. Mriganka Sur, Department of Brain and Cognitive Sciences, Massachusetts Institute of Technology, E25-235, 45 Carleton Street, Cambridge, MA 02139. E-mail: msur@ai.mit.edu.

C. L. Ho-Pao's present address: Biology Department, Trinity International University, Deerfield, IL 60015.

Copyright (C) 2001 Society for Neuroscience $\quad 0270-6474 / 01 / 213871-10 \$ 15.00 / 0$
Cramer and Sur, 1999), and the inhibition of NOS prevents sublamination (Cramer et al., 1996; Cramer and Sur, 1999). The target of NO in this system, or in the development of any other mammalian brain region, is unknown. Indeed, although NMDA receptors have been postulated to play an important role in a number of developing systems, the sequence of intracellular signals after NMDA receptor activation has not been established in the developing mammalian brain.

Evidence from the adult hippocampus (Zhuo et al., 1994; Arancio et al., 1995; Boulton et al., 1995) and developing invertebrate pathways (Gibbs and Truman, 1998; Van Wagenen and Rehder, 1999) has suggested cGMP as a possible mediator of the action of NO (Fig. 1). We reasoned that if cGMP were an intracellular target of NO that mediated plastic changes in the retinogeniculate projection of the ferret, it should (1) be developmentally regulated during sublamination, (2) be present both in the terminals of retinal ganglion cell axons and in dLGN cells to coordinate afferent-target connectivity, (3) have its expression regulated by the activity of NMDA receptors and NOS, and (4) when inhibited block sublamination. We first examined, with immunocytochemistry on acute slices in vitro, whether cGMP is expressed in the dLGN of the ferret during the period of eyespecific lamination (week 1) and sublamination (weeks 2-4). In addition, we exposed the tissue to a number of pharmacological agents that activate or inhibit the putative intracellular pathway at different points (see Fig. 1), starting with NMDA receptors and including protein kinase $\mathrm{G}$ (PKG), a likely target of cGMP (Wang and Robinson, 1997). We then determined whether cGMP is present in presynaptic retinal terminals by the use of double-labeling for cGMP and either the presynaptic protein synaptophysin or a fluorescent anterograde tracer injected into the eye to label retinal terminals unambiguously in the dLGN. Finally, we used osmotic minipumps to continuously infuse inhibitors of soluble guanylyl cyclase (sGC) or PKG in vivo to examine whether the sGC-cGMP pathway plays a functional role during sublamination. 


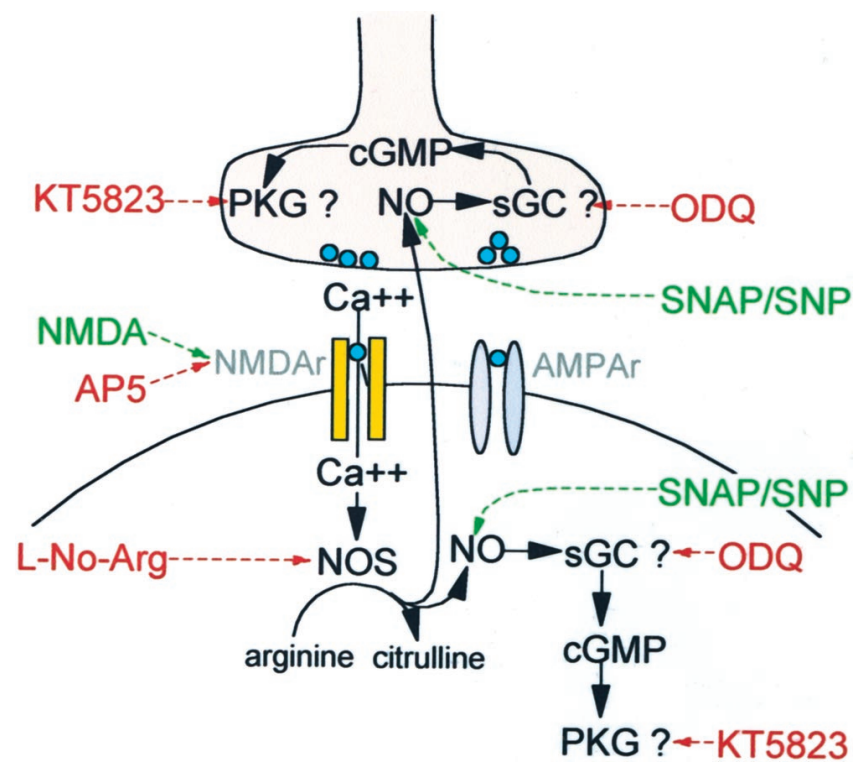

Figure 1. Schematic diagram depicting the biochemical pathway under investigation. Glutamate is released from the presynaptic terminal and activates both NMDA and AMPA receptors in the postsynaptic membrane. Activation of NMDA receptors results in an increase in the intracellular calcium concentration. This activates the calcium/ calmodulin-dependent enzyme NOS that converts arginine to citrulline and liberates NO (Bredt and Snyder, 1990; Bredt et al., 1992). Being a gas, NO cannot only act in the postsynaptic structure where it has been released but may also diff use to surrounding structures, including presynaptic terminals. [Note: NOS may also be present in presynaptic terminals (Bickford et al., 1993; Cramer et al., 1995) but for reasons of simplicity is only shown postsynaptically here.] A potential target for NO is sGC that produces cGMP (Bredt and Snyder, 1989; East and Garthwaite, 1991), and cGMP may in turn activate PKG (Butt et al., 1993; for review, see Wang and Robinson, 1997). We have investigated whether this pathway is involved in On-Off sublamination by first examining the normal developmental expression of cGMP. We then determined whether cGMP expression was modulated by the pharmacological agents shown here in red and green. Compounds shown in green activate the pathway; those shown in red inhibit the pathway. The red and green dashed lines indicate the specific component of the pathway that each reagent activates or inhibits. These results are shown in Figure 2. Finally, we infused the sGC and PKG inhibitors ODQ and KT5823, respectively, in vivo to examine whether this pathway plays a functional role in sublamination. These results are shown in Figures 5 and 6. $A M P A r$, AMPA receptor; $N M D A r$, NMDA receptor. All other abbreviations are noted in the text.

\section{MATERIALS AND METHODS}

Experiments were performed on 42 pigmented ferret kits that were bred in our colony or were born from pregnant jills purchased from Marshall Farms (Natick, MA). All experiments were performed under protocols that were approved by the Institutional Animal Care and Use Committee of Massachusetts Institute of Technology and conformed to National Institutes of Health guidelines.

Tissue preparation. Animals ranging in age from birth [postnatal day 0 (P0)] to P56 were anesthetized with sodium pentobarbitol (>100 mg/kg) and briefly perfused with chilled $\left(0-6^{\circ} \mathrm{C}\right)$ artificial CSF (ACSF) saturated with $95 \% \mathrm{O}_{2} / 5 \% \mathrm{CO}_{2}$ with the following composition (in $\mathrm{mM}$ ): $\mathrm{NaCl}, 126 ; \mathrm{KCl}, 3 ; \mathrm{NaHCO}_{3}, 25 ; \mathrm{NaH}_{2} \mathrm{PO} 4,1 ; \mathrm{CaCl}_{2}, 2 ; \mathrm{MgSO}_{4}, 1$; and dextrose, 10 . The brain was rapidly dissected out and placed in saturated, chilled ACSF, and the cortex was removed. Horizontal slices, $400 \mu \mathrm{m}$ thick, were cut through the dLGN with a vibratome. Slices were placed in saturated ACSF and allowed to rest for $1-2 \mathrm{hr}$. They were then exposed to one of the following compounds that were added to the ACSF from $1000 \times$ stock solutions to give the appropriate concentration: the nitric oxide donors sodium nitroprusside (SNP; $1 \mathrm{~mm}, 3 \mathrm{~min}$ ) or $S$-nitroso- $N$-acetyl-D,L-penicillamine (SNAP; $100 \mu \mathrm{M} ; 3 \mathrm{~min}$ ), NMDA $(30 \mu \mathrm{M} ; 1 \mathrm{~min})$, the NMDA receptor antagonist $\mathrm{D}-(-)-2$-amino-5phosphophonopentanoic acid (AP-5; $100 \mu \mathrm{M} ; 30 \mathrm{~min}$ ), the NOS inhibitor
L-nitro-arginine (L-No-Arg; $100 \mu \mathrm{M} ; 30-60 \mathrm{~min}$ ), and the selective sGC inhibitor $1 H$-[1,2,4] oxadiazolo[4,3-a]quinoxalin-1-one (ODQ; $10 \mu \mathrm{M} ; 30$ $\mathrm{min})$. In some cases, slices were preincubated for 30-60 $\mathrm{min}$ in the NOS inhibitor L-No-Arg or the SGC inhibitor ODQ for $30 \mathrm{~min}$ before the addition of NMDA or an NO donor. Control slices were incubated in ACSF for corresponding periods. Immediately after exposure to these compounds, slices were fixed in $4 \%$ paraformaldehyde in $0.1 \mathrm{M}$ sodium phosphate buffer (PB), pH 7.4, cryoprotected, and reacted for cGMP immunoreactivity.

Immunocytochemistry. For conventional light microscopy, $10-\mu \mathrm{m}$-thick sections were cut horizontally through the slices and incubated overnight at $4^{\circ} \mathrm{C}$ in a sheep anti-cGMP primary antibody (generous gift of Dr. J. de Vente) diluted 1:40,000 in phosphate buffer containing $0.5 \%$ Triton $\mathrm{X}-100$ and $2 \%$ normal rabbit serum. A biotinylated rabbit anti-sheep secondary antibody was used at a 1:200 dilution, and the reaction product was developed using ABC and VIP kits (Vector Laboratories, Burlingame, CA). An alternate series was Nissl stained and used for cell counts and measurements of cell diameter. For cell diameter, the major diameter of all cells within a randomly chosen field of view of the A layers of cGMP-labeled sections and in the adjacent Nissl-stained sections was measured at three dorsoventral levels from two animals in each age group. The range of values measured is reported. The proportion of cells expressing cGMP was calculated by counting the number of cGMPexpressing cells within a randomly chosen field of view of the A layers of cGMP-labeled sections and in the adjacent Nissl-stained sections at three dorsoventral levels from two animals in each age group. For each animal, the total number of cGMP-expressing cells counted was divided by the total number of Nissl-stained cells; each animal was treated as a separate data point. In some cases, animals were perfused briefly with saturated, chilled ACSF with or without the addition of the phosphodiesterase inhibitor isobutylmethylxanthine (IBMX; $1 \mathrm{mM}$ ) or with $0.9 \%$ saline plus $1 \mathrm{~mm}$ IBMX, followed by $4 \%$ paraformaldehyde. Tissue was sectioned and processed for cGMP immunoreactivity as described above. For double-labeling with cGMP and synaptophysin, tissue from slices was resectioned as described above and incubated in sheep anti-cGMP diluted 1:4000 in $0.1 \mathrm{M}$ PB with $2 \%$ normal rabbit serum and also containing mouse anti-synaptophysin (PharMingen, San Diego, CA) diluted 1:10 and $2 \%$ normal horse serum. After rinsing, sections were stained with a Texas Red rabbit anti-sheep secondary to reveal the cGMP labeling and a fluorescein horse anti-mouse antibody to reveal synaptophysin staining. Controls were performed to ensure that the secondary antibodies did not bind to the inappropriate primary antibody. Sections were viewed immediately on a Bio-Rad MRC-1024 confocal laser-scanning microscope using appropriate filters, and images were captured using sequential imaging. The colocalization analysis was done using commercially available software (Bio-Rad, Hercules, CA). For anterograde labeling of retinal terminals, cholera toxin subunit B (CTB) was used. Animals were anesthetized with $2-4 \%$ isofluorane in oxygen, and $10 \mu \mathrm{l}$ of $1 \%$ CTB conjugated to alexafluor 488 or 594 (Molecular Probes, Eugene, OR) was injected intraocularly. After 1-2 d, animals were killed, and slices were prepared, processed for cGMP immunohistochemistry, and analyzed on the confocal microscope as described above.

Minipump implants. Osmotic minipumps were implanted in ferrets aged between P12 and P14 as described by Cramer et al. (1996). Animals were administered $0.04 \mathrm{mg} / \mathrm{kg}$ atropine and anesthetized by inhalation of isofluorane as described above. The vehicle control solution was 50\% dimethylsulfoxide in $0.9 \%$ saline; drug-treated cases had $10 \mathrm{~mm}$ ODQ or $2 \mathrm{~mm}$ KT5823 added to the vehicle control. In animals to be used for labeling the entire retinogeniculate projection, $1-2 \mathrm{~d}$ before death, animals were anesthetized, and $10 \mu \mathrm{l}$ of $5 \%$ wheat germ agglutinin conjugated to horse-radish peroxidase (WGA-HRP; Sigma, St. Louis, MO) was injected into the eye contralateral to the minipump implant. On P25-P26, animals were killed with an injection of sodium pentobarbitol and perfused with aldehydes. The tissue was sectioned horizontally at $40-50 \mu \mathrm{m}$, and the tetramethylbenzidine reaction for WGA-HRP was performed. In cases in which individual axons were to be labeled, animals were anesthetized with an overdose of sodium pentobarbitol and perfused with chilled ACSF solution. The dLGN was exposed, and the pia overlying the ventral part of the dLGN was carefully teased away. Micropipettes coated with dried HRP were used to deposit minute quantities of HRP in this region to label small numbers of axons. After 6-8 hr, tissue was fixed in $1.25 \%$ glutaraldehyde and $1 \%$ paraformaldehyde. After cryoprotection, $100-\mu \mathrm{m}$-thick horizontal sections were cut and processed using the diaminobenzidine reaction for HRP.

Analysis. For eye injection cases, four to six consecutive sections 


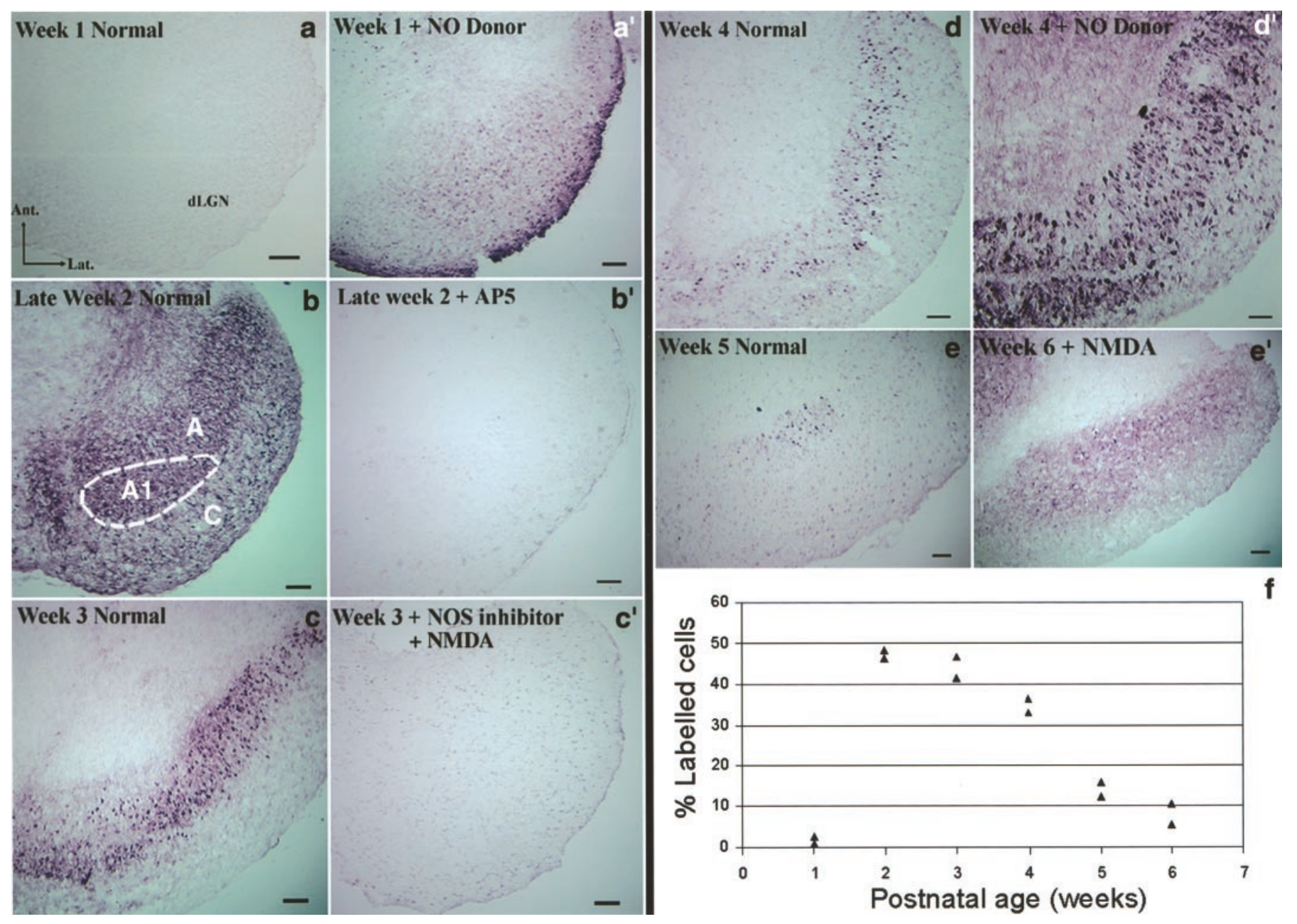

Figure 2. Developmental regulation of cGMP expression in the dLGN of the ferret. $a-e^{\prime}$, Horizontal sections are through the right thalamus, with the dLGN filling each field of view. Anterior (Ant.) is to the top, and lateral (Lat.) is to the right. $a-e$, The photomicrographs on the left of each pair show the changes in cGMP expression during normal development. Staining is very low throughout the dLGN in week $1(a)$ but increases dramatically across the dLGN, but particularly in the $A$ and $A 1$ layers, by the end of week $2(b)$; this increase reflects the staining of both cell bodies and neuropil. Staining is maintained at high levels in the $A$ layers through week $3(c)$, begins to decline during week $4(d)$, and is at low levels by week $5(e)$. $a^{\prime}-e^{\prime}$, The photomicrographs on the right of each pair show how cGMP expression may be modulated by stimulating or inhibiting the biochemical pathway under investigation at different points (see Fig. 1). During week 1, when endogenous cGMP expression is very low, exposure to an NO donor induces some cGMP expression $\left(a^{\prime}\right)$. During weeks 2 and 3, when cGMP staining is usually high, exposure to the NMDA receptor antagonist AP-5 $\left(b^{\prime}\right)$ or an NOS inhibitor $\left(c^{\prime}\right)$ reduces cGMP expression. In older animals in which normal cGMP levels have started to decrease, exposure to an NO donor $\left(d^{\prime}\right)$ or NMDA $\left(e^{\prime}\right)$ can stimulate expression of cGMP. $f$, The number of cGMP-expressing cells as a proportion of total cell number in the $A$ layers is shown. Data from two animals are shown at each age. Scale bars: $a-e^{\prime}, 100 \mu \mathrm{m}$.

through the middle one-third (dorsoventrally) of the dLGN (the region where sublamination is most evident) were scored by an experienced observer who was blind as to whether the tissue came from control or drug-treated cases. Each section was given a sublamination score between 0 and 3 based on the extent of the labeled A layer that was clearly divided into sublaminas by a palely staining intersublaminar region that approximately bisected the A layer longitudinally (e.g., a score of 1 indicates that a clear intersublaminar zone is evident across one-third of the A layer). For single-axon cases, all labeled axonal arbors that could be clearly identified as belonging to a single axon were drawn using the camera lucida at high power, and their positions and the boundaries of the A layers in the dLGN were plotted at low power. The A layers were then bisected longitudinally to approximate sublaminar boundaries in an unbiased manner for all animals. Each axon was then allotted a sublamination index between 0.5 and 1 that was based on the proportion of the height of the arbor that was contained within the preferred sublamina (i.e., the sublamina in which at least half of the arbor was contained; by the use of this system, a score of 0.5 indicates no sublamination, and a score of 1 indicates complete sublamination) by an observer who was blind as to whether the axons came from drug-treated or control animals. In addition, the total number of terminal branches was counted for each axon and compared between control and drug-treated cases. The proportion of the branches contained within the preferred sublamina was determined to give another measure of the degree of sublamination. The area contained within an envelope circumscribed by the most peripheral branches of each axon was determined and compared between cases. The proportion of the area contained within the preferred sublamina was determined to give an additional measure of the degree of sublamination.

\section{RESULTS}

The expression of cGMP is developmentally regulated in the $\mathrm{dLGN}$ of the ferret. The photomicrographs on the left-hand side of each matched pair of Figure $2 a-e^{\prime}$ illustrate the normal developmental expression of cGMP. The level of expression is very low during week 1 (Fig. 2a); however there is a dramatic increase in the degree of expression seen in both cells and neuropil by the end of week 2 (Fig. $2 b$; see also Fig. $4 a$ ). This is most prominent in the A layers (the regions that divide to form the On-Off sublaminas), but in a few cases some cellular staining was also 


\begin{tabular}{|c|c|c|c|c|c|c|c|c|c|c|c|c|}
\hline \multirow{2}{*}{$\frac{\text { Condition }}{\text { Control }}$} & \multicolumn{2}{|c|}{$\begin{array}{l}\text { Week } 1 \\
(n=7)\end{array}$} & \multicolumn{2}{|c|}{$\begin{array}{l}\text { Week } 2 \\
(n=5)\end{array}$} & \multicolumn{2}{|c|}{$\begin{array}{l}\text { Week } 3 \\
(n=4)\end{array}$} & \multicolumn{2}{|c|}{$\begin{array}{l}\text { Week } 4 \\
(n=3)\end{array}$} & \multicolumn{2}{|c|}{$\begin{array}{l}\text { Week } 5 \\
(n=2)\end{array}$} & \multicolumn{2}{|c|}{$\begin{array}{l}\text { Week } 6 \\
(n=2)\end{array}$} \\
\hline & 4 & - & 5 & +++ & 5 & $++/+++$ & 4 & ++ & 4 & + & 3 & $+/-$ \\
\hline NMDA & 3 & ++ & 4 & +++ & 4 & +++ & 3 & +++ & 3 & ++ & 3 & ++ \\
\hline AP-5 & 2 & - & 3 & - & 4 & - & 3 & - & 3 & - & 2 & - \\
\hline NO donor & 3 & ++ & 4 & +++ & 5 & +++ & 4 & +++ & 4 & ++ & 3 & ++ \\
\hline L-No-Arg & 2 & - & 2 & - & 2 & - & 3 & - & 3 & - & 2 & - \\
\hline L-No-Arg + NMDA & 0 & $\mathrm{n} / \mathrm{a}$ & 2 & - & 2 & - & 3 & - & 0 & $\mathrm{n} / \mathrm{a}$ & 0 & $\mathrm{n} / \mathrm{a}$ \\
\hline ODQ & 0 & $\mathrm{n} / \mathrm{a}$ & 2 & - & 2 & - & 0 & $\mathrm{n} / \mathrm{a}$ & 0 & $\mathrm{n} / \mathrm{a}$ & 0 & $\mathrm{n} / \mathrm{a}$ \\
\hline
\end{tabular}

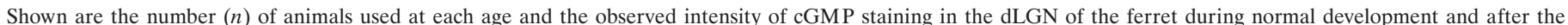



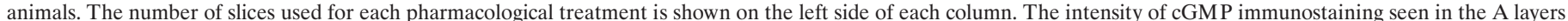

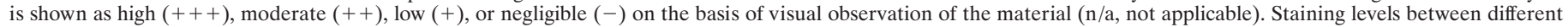
cases were extremely consistent. Data extend that presented in Figure 2.

present in the $\mathrm{C}$ layers. Expression in cells and neuropil of the $\mathrm{A}$ layers is maintained at high levels through week 3 (Fig. 2c). During week 4 (Fig. $2 d$ ) there is a marked decrease in the amount of staining seen in cells and neuropil, and this is further reduced by week 5 (Fig. $2 e$ ). Figure $2 f$ shows the number of cells expressing cGMP as a proportion of total cell number in the A layers during development. During the peak of expression (from the end of week 2 through week 3 ), $\sim 40-50 \%$ of dLGN cells express cGMP. The range of diameters of cGMP-expressing cells at selected ages (week 2, 4-14 $\mu \mathrm{m}$; week 3,6-17 $\mu \mathrm{m}$ ) is very similar to the range of cell diameters in adjacent Nissl-stained sections (week 2, 4-14 $\mu \mathrm{m}$; week 3, 4-17 $\mu \mathrm{m}$ ), suggesting that both relay cells and interneurons express cGMP.

cGMP expression is regulated by the activity of NMDA receptors and NOS. The photomicrographs on the right-hand side of the matched pairs in Figure 2 show how cGMP expression may be modulated by a number of pharmacological agents that either stimulate or inhibit the proposed signaling pathway at different points (see Fig. 1). During week 1, when endogenous cGMP expression is very low, exposure to an NO donor (Fig. $2 a^{\prime}$ ) or NMDA (Table 1) induces cGMP expression. When cGMP levels are high, from the end of week 2 and through week 3 , the addition of the NMDA receptor antagonist AP-5 (Fig. 2b') or an NOS inhibitor (L-No-Arg; Fig. $2 c^{\prime}$ ) markedly decreases cGMP expression (see also Table 1). The decrease seen after the application of an NOS inhibitor is evident despite adding NMDA to increase cGMP expression (Fig. $2 c^{\prime}$ ), indicating that NO acts downstream of NMDA receptors. Exposure to the $\mathrm{SGC}$ inhibitor ODQ during this period has a similar effect (Table 1). During week 4, the addition of an NO donor (Fig. $2 d^{\prime}$ ) or NMDA (Table 1) sharply upregulates cGMP expression. NMDA (Fig. $2 e^{\prime}$ ) or NO donors (Table 1) can also induce cGMP expression in older animals when endogenous levels are low.

cGMP is present in presumptive presynaptic terminals. Figure $3 a$ shows a high-power view of cGMP staining in the A layer of a 3-week-old animal. In addition to the staining seen in somata and dendrites, punctate terminal-like structures closely apposed to the cell bodies and proximal dendrites were also visible (arrows). Because we are particularly interested in the pathway by which NO effects changes in presynaptic structures, this was investigated in more detail. Double-labeling for cGMP and the presynaptic protein synaptophysin in conjunction with fluorescent confocal microscopy was used to investigate the localization of cGMP in presynaptic terminals. Figure $3 d$ shows cGMP labeling visualized with a secondary antibody conjugated to Texas Red. Figure $3 b$ shows the same region viewed to reveal synaptophysin staining with a secondary antibody conjugated to fluorescein. Colocalization analysis (Fig. 3c, yellow pixels) demonstrates regions where there is complete pixel-by-pixel overlap of the two signals, strongly suggesting that cGMP is indeed present in presynaptic terminals.

Because there are numerous populations of presynaptic structures in the dLGN, including brainstem inputs that are known to express NOS (Bickford et al., 1993), we also wanted to determine whether cGMP was present in retinal afferents. Accordingly, immunohistochemistry for cGMP was performed in material in which retinal axons were also labeled via an intraocular injection of the anterograde tracer CTB conjugated to a fluorescent dye. Figure $4 a$ shows a low-power image of the dLGN stained for cGMP from a 2-week-old ferret. cGMP staining is confined to the A layers; the division between the A and A1 layers is clearly visible. At high power it is seen that cGMP (Fig. 4b, red staining) stains both somata and neuropil. Retinal afferents (Fig. 4b, green label) appear as punctate structures many of which are closely apposed to cGMP-positive structures. As would be expected, only a small proportion of the amount of presynaptic labeling seen with synaptophysin staining is visible after retinal injections. In one case, retinal terminal-like structures can be seen encircling a dendrite (Fig. $4 b$, large arrow). Figure $4 c$ is a colocalization image. Yellow pixels mark regions where there is complete pixel-by-pixel overlap of the cGMP staining and CTB labeling from the retina. Many of the labeled retinal afferents also show staining for cGMP strongly suggesting that cGMP is indeed present in retinal terminals; some examples of these are highlighted by corresponding pairs of arrowheads in Figure 4, $b$ and $c$. Not all retinal terminals are positive for cGMP; a few examples of retinal terminals that do not show cGMP expression are marked by corresponding pairs of small arrows (Fig. 4b,c). Because of differences in the techniques, it is unclear whether all of the cGMP staining seen associated with the presynaptic protein synaptophysin in Figure $3 b$ can be accounted for by that located in retinal terminals or whether other inputs to the dLGN also express cGMP presynaptically at this stage of development.

Together, the above results indicate that sGC and cGMP are present in the right place (presynaptic retinal terminals and postsynaptic dLGN cells) at the right time (postnatal weeks 2-4) to play a role in sublamination. We next investigated a functional role for this pathway during sublamination by using osmotic minipumps to infuse continuously either a specific inhibitor of sGC, ODQ, or control vehicle solution into the dLGN of ferrets from the end of week 2. In initial experiments, animals were 

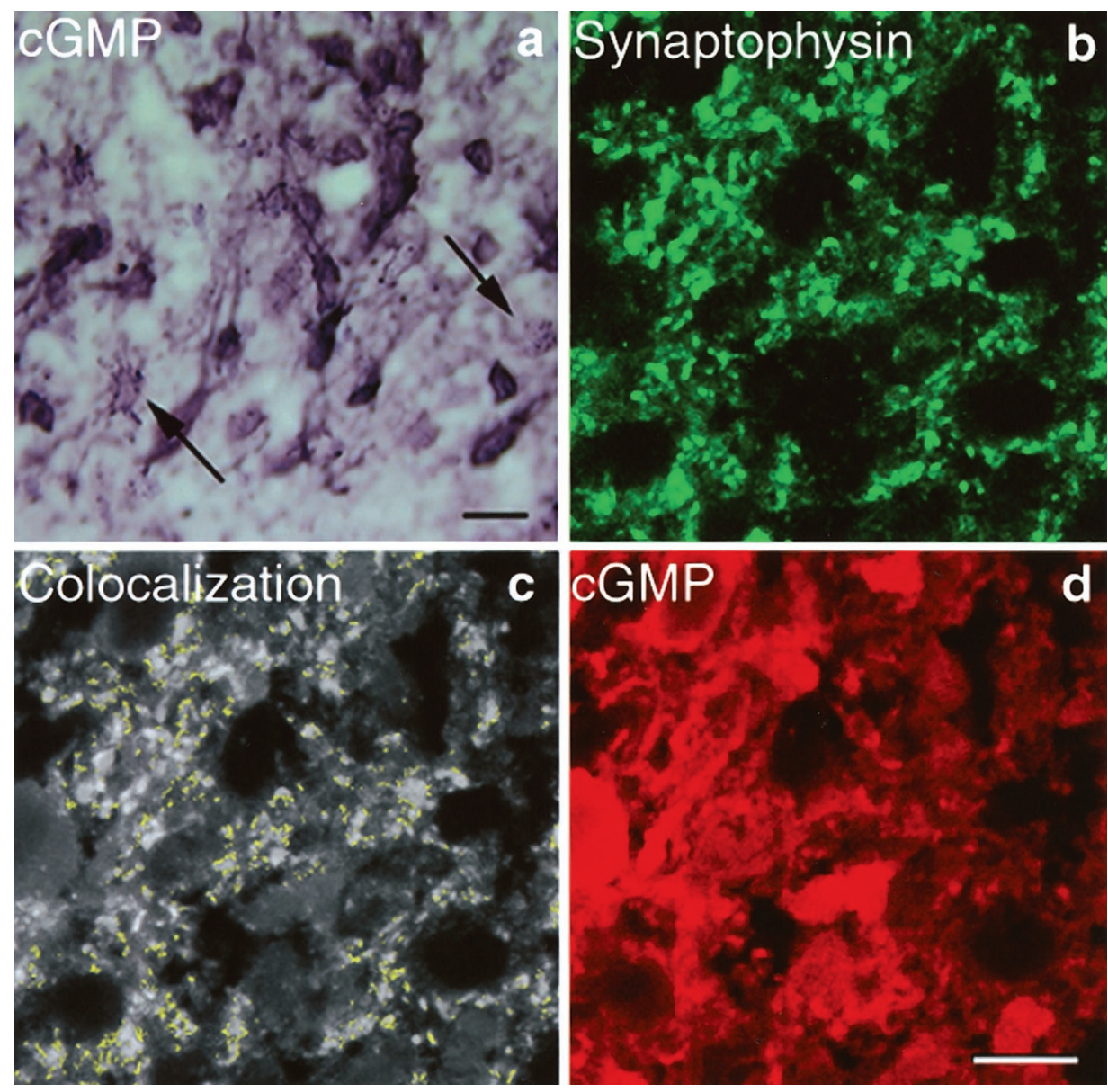

Figure 3. High-power views of sections through the dLGN of the ferret during the period of On-Off sublamination. $a$, Conventional light microscopy of a section stained for cGMP showing bouton-like structures closely apposed to neuronal somata and proximal dendrites (arrows). Somata and dendrites are also stained. $b$, Confocal image of the A layer of the dLGN stained for the presynaptic protein synaptophysin. $c$, Colocalization analysis preformed on the images shown in $b$ and $d$. Yellow dots indicate regions where there is complete pixel-by-pixel overlap of the cGMP and synaptophysin signals. $d$, The same area shown in $b$ viewed to reveal cGMP staining seen under the confocal microscope with a fluorescent secondary antibody. Both cells and punctate, bouton-like structures are labeled. Scale bars: $a-d, 10 \mu \mathrm{m}$. perfused 1 week after implantation of the minipump, and immunohistochemistry for cGMP was performed to confirm that the in vivo inf usion of ODQ did indeed block cGMP production. It was found that infusion of $10 \mathrm{~mm}$ ODQ (concentration inside the minipump) completely blocked cGMP expression, whereas infusion of $2 \mathrm{~mm}$ ODQ did not (data not shown); thus $10 \mathrm{~mm}$ was the dosage used for subsequent experiments. Animals were allowed to survive until midway through week 4 , and retinogeniculate terminals were labeled by an injection of tracer into the eye contralateral to the minipump. Selected sections (see Materials and Methods) were given a sublamination score between 0 and 3 , with a score of 3 indicating maximal sublamination.

The in vivo inhibition of sGC prevents sublamination; these results are shown in Figure 5. After this treatment, there was no observable difference in the appearance of the animals or in brain morphology between drug-treated and control cases. Eye injections demonstrated that retinal axons were clearly confined to the dLGN. Because only the projections from the eye contralateral to the minipump were labeled, it was clear that there was no observable difference in the appearance or the degree of segregation present in the eye-specific layers (compare appearance of A1 layers in Fig. $5 a-c$ ). There was also no apparent difference in the size or morphology of the dLGN itself. There was, however, a pronounced effect on the degree of sublamination. A palely staining intersublaminar zone, separating the inner $(A i)$ and outer $(A o)$ sublaminas is present in sections from control animals (Fig. $5 a$, arrowheads). This region is not discernable in sections from ODQ-treated animals (Fig. $5 b$ ). The population data are shown graphically in Figure 5, bottom. The sublamination scores for control animals $(n=4$; mean $=2.13)$ were essentially the same as those reported previously (Cramer et al., 1996) for normal animals $(n=6$; mean $=2.1)$ but were significantly greater than those for ODQ-treated animals $(n=6$; mean $=0.36$; $p<0.01$, MannWhitney $U$ test), indicating that activation of sGC-cGMP is required for the segregation of retinogeniculate axons into sublaminas. We also investigated whether PKG is involved in the signaling pathway. For this the PKG inhibitor KT5823 or control vehicle solution was infused. As with ODQ treatment, the overall appearance of the retinal projection and that of the dLGN itself were similar to controls (Fig. 5a). However, treatment with KT5823 disrupted sublamination (Fig. 5c). Sublamination scores from animals treated with KT5823 $(n=5$; mean $=0.46)$ were significantly lower ( $p<0.01$, Mann-Whitney $U$ test) than those from control animals (Fig. 5, bottom).

Previous studies have demonstrated that the disruption of sublamina formation after the blockade of NMDA receptors or NOS is the manifestation of retinogeniculate arbors being inappropriately positioned in the dLGN with respect to intersublaminar boundaries (Hahm et al., 1991, 1999; Cramer et al., 1996). We wanted to ascertain whether the disruption of sublamination seen here after blockade of the sGC-cGMP pathway was a reflection of changes occurring in the organization of individual presynaptic axons. Accordingly, individual retinogeniculate terminal arbors from control and ODQ-treated animals were labeled with HRP, and their positions with respect to the intersublaminar boundaries were plotted. Fifteen axons were reconstructed from each condition. There was no observable difference in the appearance of the axons themselves between drug-treated and control ani- 



Figure 4. Confocal images of horizontal sections through the dLGN of a P14 ferret. $a$, Low-power image showing the pattern of cGMP staining when visualized with a fluorescent secondary antibody. Orientation is as described for Figure 2. Note that the label is clearly confined to the $A$ layers. Layers are as indicated, and the border of the dLGN is marked with a dashed line. The arrowhead indicates a small photobleached area in the $A$ layer where the images shown in $b$ and $c$ were taken. $b$, High-power confocal image of the dLGN stained for cGMP (red staining) and labeled with CTB conjugated to a fluorescent tag (green staining). The image is
Table 2. Measures of mean retinogeniculate arbor size

\begin{tabular}{lccc} 
Parameter measured & $\begin{array}{l}\text { Control } \\
(n=15)\end{array}$ & $\begin{array}{l}\text { ODQ treated } \\
(n=15)\end{array}$ & Probability \\
\hline Arbor area $\left(\mu \mathrm{m}^{2}\right)$ & $6670 \pm 510$ & $6535 \pm 660$ & $p>0.8$ \\
Arbor height $(\mu \mathrm{m})$ & $120 \pm 9.7$ & $146 \pm 12.8$ & $p>0.1$ \\
Terminal branches & $51 \pm 3.79$ & $61.5 \pm 6.3$ & $p>0.2$
\end{tabular}

Measurements of mean retinogeniculate arbor size $( \pm \mathrm{SE})$ for reconstructed axons from ODQ-treated and control animals are shown. Fifteen axons were reconstructed for each condition. Estimates of size were determined from reconstructed axons according to three criteria: arbor area, arbor height, and number of terminal branches. There was no statistically significant difference in arbor size between control and drug-treated animals by the use of any of these measures.

mals, nor was there a significant difference in the size of the axonal arbors whether measured in terms of arbor area, arbor height, or the total number of terminal branches $(p>0.1$ for all measurements; see Table 2). The values for axonal area and height are similar to those reported for normal animals of a similar age (Hahm et al., 1999). There was, however, a marked difference in the location of the axonal arbors between the drugtreated and control animals when examined with respect to the position of intersublaminar boundaries. Examples are given in Figure $6, a$ and $b$. The degree of sublamination of each axonal arbor was measured according to three criteria: arbor height, arbor area, and the number of terminal branches. The proportion of each arbor contained within the preferred sublamina according to each of these criteria was used to assign three sublamination indices per axon; an index of 0.5 indicates equal spread across the two sublaminas, whereas an index of 1 signifies complete segregation within a single sublamina. There was no significant difference between any of the sublamination indices obtained by use of the three criteria within the drug-treated $(p>0.6)$ or control $(p>0.3)$ groups (two-tailed $t$ tests). Mean sublamination indices $( \pm \mathrm{SE})$ for axons from control animals were the following: area $=$ $0.969 \pm 0.019$, height $=0.966 \pm 0.021$, and number of terminal branches $=0.978 \pm 0.013$. Corresponding values from ODQtreated animals were the following: area $=0.744 \pm 0.058$, height $=0.773 \pm 0.051$, and number of terminal branches $=$ $0.784 \pm 0.053$. These values are plotted in Figure $6 c$. There was, however, a significant difference between the corresponding sublamination indices of control and drug-treated animals on the basis of area ( $p<0.01$, Mann-Whitney $U$ test), height ( $p<0.01$, Mann-Whitney $U$ test), and the number of terminal branches ( $p<0.01$, Mann-Whitney $U$ test). The sublamination indices for arbor height in control animals were similar to those reported previously for normal animals (Hahm et al., 1991), whereas those for ODQ-treated animals were similar to those reported after inhibition of NOS (Cramer et al., 1996).

taken from the region indicated by the arrowhead in $a$. Punctate retinal terminals can be seen closely apposed to postsynaptic structures, many of which are stained for cGMP. In one case a dendrite can clearly be seen emanating from a soma (large arrow) encircled by a number of retinal terminals. $c$, Colocalization analysis image of the cGMP staining and CTB labeling shown in $b$. Regions of complete pixel-by-pixel overlap of the two images are shown by yellow pixels. Many of the retinal-labeled terminals are colocalized with cGMP staining, strongly suggesting that cGMP is present in retinal terminals. Some examples of these are indicated by corresponding pairs of arrowheads in $b$ and $c$. Not all retinal terminals express cGMP however; some examples of these are indicated by the small arrows in $b$ and $c$. Scale bars: $a, 200 \mu \mathrm{m} ; b, c, 10 \mu \mathrm{m}$. 

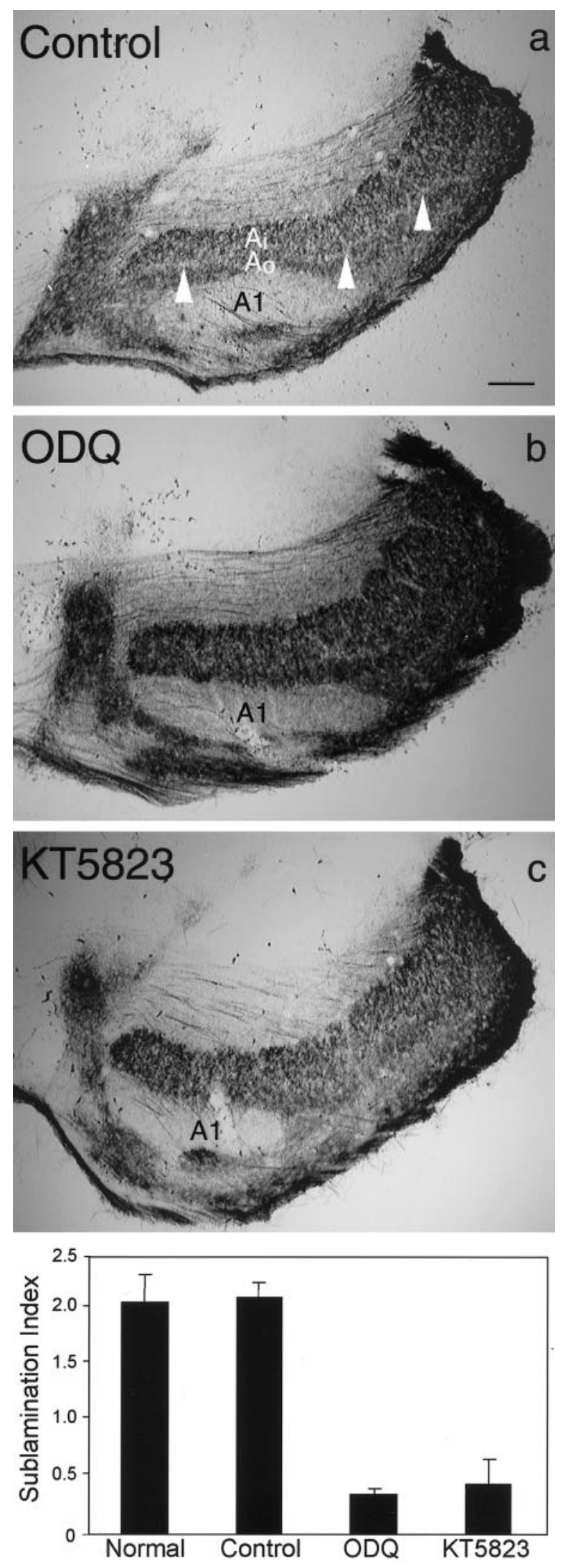

Figure 5. Effects of in vivo blockade of sGC and PKG. $a-c$, Representative sections from control ( $a$ ), ODQ-treated $(b)$, and KT5823-treated (c) cases labeled with an intraocular injection of WGA-HRP into the contralateral eye. Label is confined to the $A$ layer of the dLGN in all cases. A lightly stained intersublaminar zone is clearly evident separating the inner

\section{DISCUSSION}

This study has investigated whether the sGC-cGMP-PKG pathway is involved in mediating activity-dependent structural rearrangements downstream of NMDA receptors and NOS. We have demonstrated that there is a transient upregulation of cGMP expression in the presynaptic and postsynaptic structures of the A layers of the dLGN in the ferret that closely matches the period of retinogeniculate axon sublamination and, importantly, that the expression of cGMP is regulated by the activity of NMDA receptors and NOS. Furthermore, we have shown using osmotic minipumps to continuously infuse specific inhibitors of sGC or PKG that the activity of these molecules is required for the normal process of On-Off sublamination in vivo. Together, these results strongly suggest that the sGC-cGMP-PKG pathway acts downstream of NMDA receptors and NO and plays a critical role in the refinement of connections in the developing retinogeniculate pathway.

Before proceeding further, we should consider whether the observed effect of the infusion of ODQ and KT5823 on the segregation of retinal axons into sublaminas demonstrates a specific requirement for $\mathrm{sGC}$ and $\mathrm{PKG}$ during sublamination or whether axonal growth was nonspecifically dysregulated. We believe that the effects on sublamination demonstrate a specific requirement for $\mathrm{sGC}$ and $\mathrm{PKG}$ during sublamination for a number of reasons. Minipumps filled with vehicle solution were used to control for effects of the surgery, the minipump implantation, and the chronic infusion of the same volume of carrier solution. There were no differences in the appearance of the animals or of the brains at the time of perfusion. Retinal axons were clearly confined to the dLGN in both groups, and no difference in the size or the degree of segregation present in the eye-specific layers could be observed. This suggests that despite the reported roles for cyclic nucleotides in axon pathfinding (Song et al., 1997, 1998; Van Wagenen and Rehder, 1999), retinal axons can clearly still recognize the cues that allow them to distinguish between thalamic nuclei and layers within the dLGN. This is interesting with respect to the report that activity is required not only for the formation (Shatz and Stryker, 1988; Sretavan et al., 1988; Penn et al., 1998) but also for the maintenance (Chapman, 2000) of eye-specific layers in the dLGN and suggests that although these changes occurred during a similar window of development, very different mechanisms are involved than those reported here. After treatment with ODQ, there was no evidence that the morphology of the retinal axons (apart from the degree of sublamination) was different between drug-treated and control animals. Similarly, there were no apparent differences in the size or shape of the dLGN. Because we did not examine dendritic morphology in this study, we cannot exclude the possibility that the changes in axonal structure might be secondary to changes that may have occurred in dendrites of dLGN neurons. However, because cGMP is present in retinal terminals and retinal termi-

$(A i)$ and outer $(A O)$ sublaminas in the control section (indicated by the arrowheads in $a$ ). No similar region can be seen extending across the representative sections from the ODQ-treated $(b)$ or KT5823-treated $(c)$ animals. Anterior is to the top, and lateral to the right. Bottom, Bar graph plotting mean sublamination scores and SEM from the three groups and from normal animals [data for normals taken with permission from Cramer et al. (1996)]. Sections from control animals had a degree of sublamination similar to that reported for normal animals, whereas sublamination was significantly decreased in ODQ- or KT5823-treated animals $(p<0.01$, Mann-Whitney $U$ test). Scale bar: $a-c, 100 \mu \mathrm{m}$. 

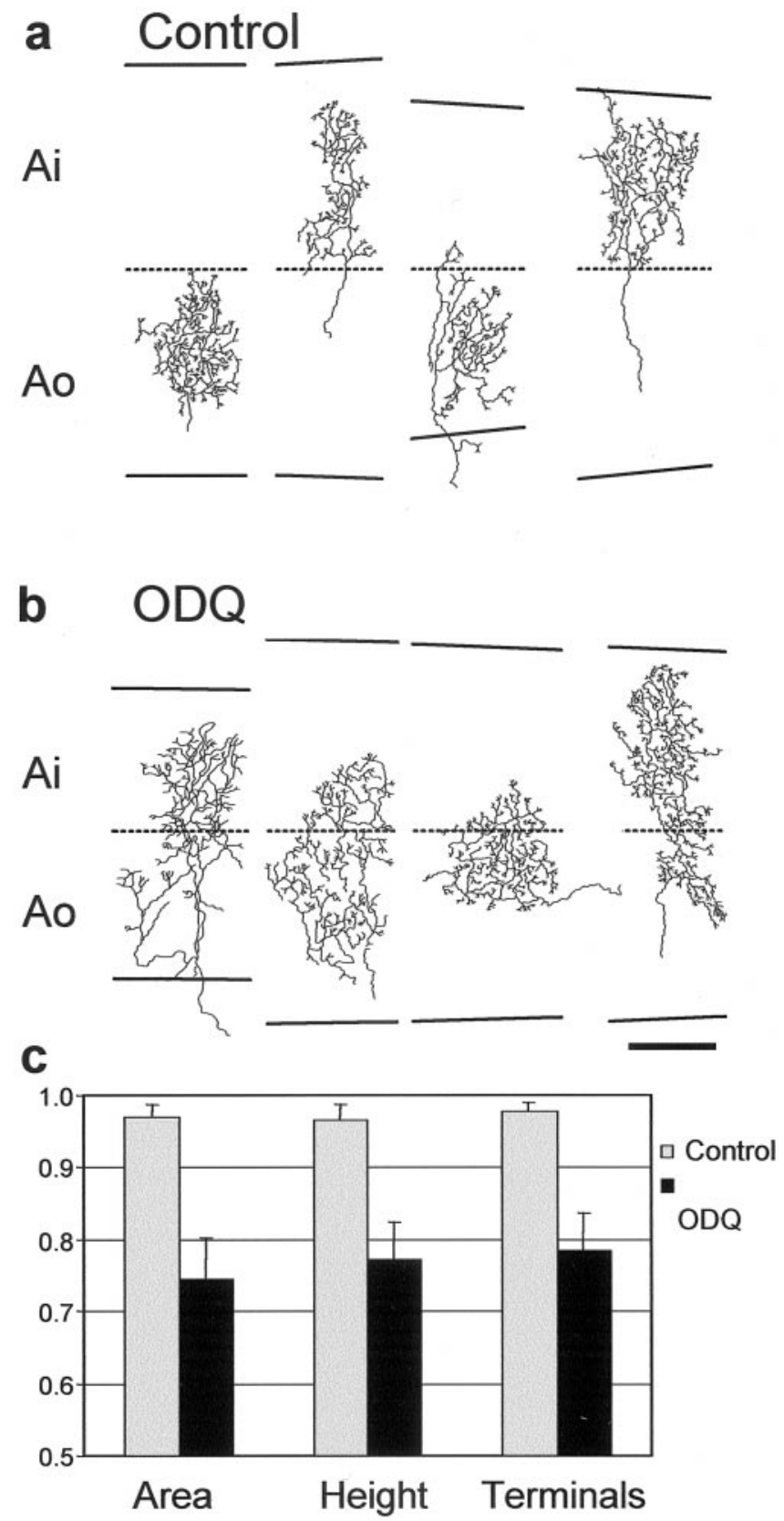

Figure 6. $a, b$, Examples of individual retinogeniculate axons labeled with HRP from control $(a)$ and ODQ-treated $(b)$ animals. The laminar (solid lines) and sublaminar (dashed lines) borders are shown. There are no apparent differences in the overall appearance or significant differences in size (see Table 2) of the axons between groups; however axons from control animals primarily conform to the sublaminar boundaries, whereas those from ODQ-treated animals do not. $c$, Bar graph plotting mean sublamination indices and SEM for control and ODQ-treated animals. Three sublamination indices were determined separately for arbor area, arbor height, and the number of terminations. The sublamination indices of ODQ-treated animals for all three criteria are significantly lower than those for controls (see Results). Scale bar: $a, b, 50 \mu \mathrm{m}$.

nals lose their ability to respond to normal activity-dependent cues after infusion of a cGMP inhibitor, there is at least the capacity for the effects to be orchestrated within the terminal itself. In fact, the presence of cGMP in both retinal terminals and dendrites of dLGN cells during a critical developmental period places this pathway in a unique position to coregulate changes in presynaptic and postsynaptic structures. This issue is discussed further below.

\section{cGMP as a target of NMDA receptor activation and nitric oxide}

The regulation of cGMP expression during development, and as a signal downstream of NMDA receptors and NO, has not previously been examined in a system that relies extensively on the activity-dependent refinement of connections, such as the visual system of the mammalian brain (Katz and Shatz, 1996). Indeed, the intracellular signals that are developmentally induced by NMDA receptor activation in the mammalian brain remain unknown. Furthermore, the effect of sGC blockade on connectivity and pattern formation has not been examined previously in vivo.

The mechanisms by which activity-dependent rearrangements take place in the developing visual system have often been suggested to have much in common with the mechanisms of hippocampal NMDA receptor-dependent synaptic plasticity (Bear, 1996; Cramer and Sur, 1996; Katz and Shatz, 1996). Many in vitro physiological studies have indicated a role for NO and/or sGC in synaptic plasticity downstream of NMDA receptors in the hippocampus (Schuman and Madison, 1991; Haley et al., 1992; Schuman et al., 1994; Zhuo et al., 1994; Arancio et al., 1995, 1996; Boulton et al., 1995; Kantor et al., 1996; Son et al., 1996; Lu et al., 1999), dentate gyrus (Wu et al., 1997, 1998), cerebellum (Crepel and Jaillard, 1990; Shibuki and Okada, 1991; Daniel et al., 1993; Blond et al., 1997; Lev-Ram et al., 1997), neocortex (Wakatsuki et al., 1998), and the corticostriatal pathway (Calabresi et al., 1999), although there have been some conflicting reports on the roles of these molecules (Chetkovich et al., 1993; Bannerman et al., 1994; Schuman et al., 1994; Kleppisch et al., 1999). Differences in the protocols used may explain some of the discrepancies in the reported roles of NO and cGMP in synaptic plasticity (Gribkoff and Lum-Ragan, 1992; Lum-Ragan and Gribkoff, 1993; Son et al., 1998; Wilson et al., 1999).

Although the primary action of cGMP is considered to be an increase in the intracellular concentration of $\mathrm{PKG}$, pathways of $\mathrm{NO}$ action other than sGC-cGMP-PKG are possible (Wang and Robinson, 1997). A number of studies have reported that PKG activity is required for long-term potentiation (LTP) (Zhuo et al., 1994; Lu et al., 1999) and depression (Wu et al., 1998; Calabresi et al., 1999). Recently an elegant study has demonstrated a specific requirement for PKG activity in the presynaptic neuron (Arancio et al., 2001). This is somewhat contrary to results that have demonstrated that hippocampal LTP is normal in mice lacking the genes for isoforms of PKG (Kleppisch et al., 1999). One possibility is that under certain conditions, NO may act via an sGC-cGMP-PKG-independent pathway such as adenosine diphosphate ribosyl transferase (Schuman et al., 1994; Kleppisch et al., 1999). cGMP may also exert effects independent of PKG, including actions mediated by cyclic nucleotide-gated ion channels and cGMP-regulated phosphodiesterases (Wang and Robinson, 1997). cGMP has recently been reported to exert PKGindependent effects on the response properties of AMPA receptors (Lei et al., 2000), and nitric oxide has been shown to modify neurotransmitter release (Montague et al., 1994) via both PKG-dependent and PKG-independent mechanisms (Kamisaki et al., 1995; Sequeira et al., 1999). In the present study, the sGC and PKG inhibitors ODQ and KT5823, respectively, both disrupted sublamination to a similar degree (Fig. 5, bottom), suggesting that cGMP and PKG are both involved in the refinement of connections in the retinogeniculate pathway.

Developmentally, NO has been shown to play a role in neurite outgrowth (Hess et al., 1993; Hindley et al., 1997) and in the 
refinement of connections. In the retinotectal pathway of the chick, NOS blockade results in the retention of an ipsilateral pathway that is normally removed via an NMDA-dependent mechanism (Wu et al., 1994; Ernst et al., 1999). Similar results were reported recently in rodents (Vercelli et al., 2000). In vitro, $\mathrm{NO}$ acts in a cGMP-dependent manner to promote neurite outgrowth in hippocampal cells (Hindley et al., 1997) and plays a role in the patterning of connections from the photoreceptors to the optic lobe in Drosophila (Gibbs and Truman, 1998). Recently, cGMP has been shown to modulate the responses of growth cones to the semaphorins (Song et al., 1998), and cyclic nucleotides can modulate the responses of growing axons to neurotrophic factors (Song et al., 1997) and to the netrins (Hopker et al., 1999).

Currently, little is known about the roles of PKG during development, although an isoform of PKG is expressed at high levels in the thalamus (El-Husseini et al., 1999) and PKG is well placed to influence membrane and synaptic function (for review, see Wang and Robinson, 1997). A number of possible sites of action of PKG exist, such as regulation of gene expression (Gudi et al., 1999) and protein phosphorylation, including phosphorylation of NOS, thus influencing its activity (Dinerman et al., 1994; Butt et al., 2000). PKG may also regulate changes in the cytoskeleton, because its known substrates include the intermediate filament protein vimentin (MacMillan-Crow and Lincoln, 1994) and the focal adhesion vasodilator-stimulated phosphoprotein VASP (Butt et al., 1994). Other work has found that PKG can influence cell growth by regulating the activity of the mitogen-activated protein kinase (Suhasini et al., 1998).

\section{Presynaptic and postsynaptic effects of cGMP}

We found that cGMP expression was upregulated in presumptive retinal axon terminals in the dLGN of the ferret during the period of On-Off sublamination. This suggests that its synthetic enzyme sGC is a target of the retrograde messenger NO in this system as has been reported in the hippocampus (Arancio et al., 1996), although the staining seen in somata and dendrites suggests there may also be postsynaptic effects. Indeed, the development of specific connections between retinal afferents and dLGN target cells involves both presynaptic and postsynaptic regulation of synaptic contacts by activity (Dalva et al., 1994; Rocha and Sur, 1995). In particular, application of NMDA receptor antagonists during the third postnatal week results in dramatic increases in spine density within hours (Rocha and Sur, 1995). These effects of NMDA receptor activity on spines are mediated via an NOdependent pathway, because the application of NOS inhibitors has similar effects (Cramer and Sur, 1997b). Significantly, the effects of NO on postsynaptic structures are most pronounced during week 3 when cellular cGMP levels are at their peak, suggesting that this pathway is likely to be involved in regulating postsynaptic structural changes in response to activity.

An interesting observation made here is that cGMP expression remains low during the period of eye-specific layer formation (week 1). Although reported to be dependent on the presence of spontaneous bursts of retinal activity (Penn et al., 1998; but see also Cook et al., 1999) that occur before eye opening (Galli and Maffei, 1988; Meister et al., 1991; Wong et al., 1995), this process does not involve either NMDA receptors (Smetters et al., 1994) or NOS activity (Cramer et al., 1996). The lack of cGMP staining during this period concurs with these latter results and is consistent with the sGC-cGMP-PKG pathway playing a role during a specific phase of development in conjunction with NO. It also implies that different mechanisms may underlie the processes of eye-specific layer formation and On-Off sublamination. Importantly, the data provided here demonstrate a sequence of signaling steps in one developmental system (On-Off sublamination in the retinogeniculate pathway) that link afferent and target activity, NMDA receptor activation, NO synthesis, and subsequently cGMP and PKG activation as key steps in the structural changes that enable pattern formation.

\section{REFERENCES}

Arancio O, Kandel ER, Hawkins RD (1995) Activity-dependent longterm enhancement of transmitter release by presynaptic $3^{\prime}, 5^{\prime}$-cyclic GMP in cultured hippocampal neurons. Nature 376:74-80.

Arancio O, Kiebler M, Lee CJ, Lev-Ram V, Tsien RY, Kandel ER, Hawkins RD (1996) Nitric oxide acts directly in the presynaptic neuron to produce long-term potentiation in cultured hippocampal neurons. Cell 87:1025-1035.

Arancio O, Antonova I, Gambaryan S, Lohmann SM, Wood JS, Lawrence DS, Hawkins RD (2001) Presynaptic role of cGMP-dependent protein kinase during long-lasting potentiation. J Neurosci 21:143-149.

Bannerman DM, Chapman PF, Kelly PA, Butcher SP, Morris RG (1994) Inhibition of nitric oxide synthase does not prevent the induction of long-term potentiation in vivo. J Neurosci 14:7415-7425.

Bear MF (1996) NMDA-receptor-dependent synaptic plasticity in the visual cortex. Prog Brain Res 108:205-218.

Bickford ME, Gunluk AE, Guido W, Sherman SM (1993) Evidence that cholinergic axons from the parabrachial region of the brainstem are the exclusive source of nitric oxide in the lateral geniculate nucleus of the cat. J Comp Neurol 334:410-430.

Blond O, Daniel H, Otani S, Jaillard D, Crepel F (1997) Presynaptic and postsynaptic effects of nitric oxide donors at synapses between parallel fibres and Purkinje cells: involvement in cerebellar long-term depression. Neuroscience 77:945-954.

Boulton CL, Southam E, Garthwaite J (1995) Nitric oxide-dependent long-term potentiation is blocked by a specific inhibitor of soluble guanylyl cyclase. Neuroscience 69:699-703.

Bredt DS, Snyder SH (1989) Nitric oxide mediates glutamate-linked enhancement of cGMP levels in the cerebellum. Proc Natl Acad Sci USA 86:9030-9033.

Bredt DS, Snyder SH (1990) Isolation of nitric oxide synthetase, a calmodulin-requiring enzyme. Proc Natl Acad Sci USA 87:682-685.

Bredt DS, Ferris CD, Snyder SH (1992) Nitric oxide synthase regulatory sites. Phosphorylation by cyclic AMP-dependent protein kinase, protein kinase $\mathrm{C}$, and calcium/calmodulin protein kinase; identification of flavin and calmodulin binding sites. J Biol Chem 267:10976-10981.

Butt E, Geiger J, Jarchau T, Lohmann SM, Walter U (1993) The cGMPdependent protein kinase: gene, protein, and function. Neurochem Res $18: 27-42$.

Butt E, Abel K, Krieger M, Palm D, Hoppe V, Hoppe J, Walter U (1994) cAMP- and CGMP-dependent protein kinase phosphorylation sites of the focal adhesion vasodilator-stimulated phosphoprotein (VASP) in vitro and in intact human platelets. J Biol Chem 269:14509-14517.

Butt E, Bernhardt M, Smolenski A, Kotsonis P, Frohlich LG, Sickmann A, Meyer HE, Lohmann SM, Schmidt HH (2000) Endothelial nitricoxide synthase (type III) is activated and becomes calcium independent upon phosphorylation by cyclic nucleotide-dependent protein kinases. J Biol Chem 275:5179-5187.

Calabresi P, Gubellini P, Centonze D, Sancesario G, Morello M, Giorgi M, Pisani A, Bernardi G (1999) A critical role of the nitric oxide/ cGMP pathway in corticostriatal long-term depression. J Neurosci 19:2489-2499.

Chapman B (2000) Necessity for afferent activity to maintain eyespecific segregation in ferret lateral geniculate nucleus. Science 287:2479-2482.

Chetkovich DM, Klann E, Sweatt JD (1993) Nitric oxide synthaseindependent long-term potentiation in area CA1 of hippocampus. NeuroReport 4:919-922.

Cook PM, Prusky G, Ramoa AS (1999) The role of spontaneous retinal activity before eye opening in the maturation of form and function in the retinogeniculate pathway of the ferret. Vis Neurosci 16:491-501.

Cramer KS, Sur M (1996) The role of NMDA receptors and nitric oxide in retinogeniculate development. Prog Brain Res 108:235-244.

Cramer KS, Sur M (1997a) Blockade of afferent impulse activity disrupts on/off sublamination in the ferret lateral geniculate nucleus. Brain Res Dev Brain Res 98:287-290.

Cramer KS, Sur M (1997b) Blockade of nitric oxide synthase alters dendritic morphology in the ferret lateral geniculate nucleus. Soc Neurosci Abstr 23:1159.

Cramer KS, Sur M (1999) The neuronal form of nitric oxide synthase is required for pattern formation by retinal afferents in the ferret lateral geniculate nucleus. Brain Res Dev Brain Res 116:79-86.

Cramer KS, Moore CI, Sur M (1995) Transient expression of NADPH- 
diaphorase in the lateral geniculate nucleus of the ferret during early postnatal development. J Comp Neurol 353:306-316.

Cramer KS, Angelucci A, Hahm JO, Bogdanov MB, Sur M (1996) A role for nitric oxide in the development of the ferret retinogeniculate projection. J Neurosci 16:7995-8004.

Crepel F, Jaillard D (1990) Protein kinases, nitric oxide and long-term depression of synapses in the cerebellum. NeuroReport 1:133-136.

Dalva MB, Ghosh A, Shatz CJ (1994) Independent control of dendritic and axonal form in the developing lateral geniculate nucleus. J Neurosci $14: 3588-3602$.

Daniel H, Hemart N, Jaillard D, Crepel F (1993) Long-term depression requires nitric oxide and guanosine $3^{\prime}: 5^{\prime}$ cyclic monophosphate production in rat cerebellar Purkinje cells. Eur J Neurosci 5:1079-1082.

Dinerman JL, Steiner JP, Dawson TM, Dawson V, Snyder SH (1994) Cyclic nucleotide dependent phosphorylation of neuronal nitric oxide synthase inhibits catalytic activity. Neuropharmacology 33:1245-1251.

East SJ, Garthwaite J (1991) NMDA receptor activation in rat hippocampus induces cyclic GMP formation through the L-arginine-nitric oxide pathway. Neurosci Lett 123:17-19.

El-Husseini AE, Williams J, Reiner PB, Pelech S, Vincent SR (1999) Localization of the cGMP-dependent protein kinases in relation to nitric oxide synthase in the brain. J Chem Neuroanat 17:45-55.

Ernst AF, Wu HH, El-Fakahany EE, McLoon SC (1999) NMDA receptor-mediated refinement of a transient retinotectal projection during development requires nitric oxide. J Neurosci 19:229-235.

Galli L, Maffei L (1988) Spontaneous impulse activity of rat retinal ganglion cells in prenatal life. Science 242:90-91.

Gibbs SM, Truman JW (1998) Nitric oxide and cyclic GMP regulate retinal patterning in the optic lobe of Drosophila. Neuron 20:83-93

Gribkoff VK, Lum-Ragan JT (1992) Evidence for nitric oxide synthase inhibitor-sensitive and insensitive hippocampal synaptic potentiation. J Neurophysiol 68:639-642.

Gudi T, Hong GK, Vaandrager AB, Lohmann SM, Pilz RB (1999) Nitric oxide and cGMP regulate gene expression in neuronal and glial cells by activating type II cGMP-dependent protein kinase. FASEB J 13:2143-2152.

Hahm JO, Langdon RB, Sur M (1991) Disruption of retinogeniculate afferent segregation by antagonists to NMDA receptors. Nature 351:568-570

Hahm JO, Cramer KS, Sur M (1999) Pattern formation by retinal afferents in the ferret lateral geniculate nucleus: developmental segregation and the role of $N$-methyl-D-aspartate receptors. J Comp Neurol 411:327-345.

Haley JE, Wilcox GL, Chapman PF (1992) The role of nitric oxide in hippocampal long-term potentiation. Neuron 8:211-216.

Hess DT, Patterson SI, Smith DS, Skene JH (1993) Neuronal growth cone collapse and inhibition of protein fatty acylation by nitric oxide. Nature 366:562-565.

Hindley S, Juurlink BH, Gysbers JW, Middlemiss PJ, Herman MA, Rathbone MP (1997) Nitric oxide donors enhance neurotrophininduced neurite outgrowth through a cGMP-dependent mechanism. J Neurosci Res 47:427-439.

Hopker VH, Shewan D, Tessier-Lavigne M, Poo M, Holt C (1999) Growth-cone attraction to netrin-1 is converted to repulsion by laminin-1. Nature 401:69-73.

Kamisaki Y, Wada K, Nakamoto K, Itoh T (1995) Nitric oxide inhibition of the depolarization-evoked glutamate release from synaptosomes of rat cerebellum. Neurosci Lett 194:5-8.

Kantor DB, Lanzrein M, Stary SJ, Sandoval GM, Smith WB, Sullivan BM, Davidson N, Schuman EM (1996) A role for endothelial NO synthase in LTP revealed by adenovirus-mediated inhibition and rescue. Science 274:1744-1748.

Katz LC, Shatz CJ (1996) Synaptic activity and the construction of cortical circuits. Science 274:1133-1138.

Kleppisch T, Pfeifer A, Klatt P, Ruth P, Montkowski A, Fassler R, Hofmann $F$ (1999) Long-term potentiation in the hippocampal CA1 region of mice lacking cGMP-dependent kinases is normal and susceptible to inhibition of nitric oxide synthase. J Neurosci 19:48-55.

Lei S, Jackson MF, Jia Z, Roder J, Bai D, Orser BA, MacDonald JF (2000) Cyclic GMP-dependent feedback inhibition of AMPA receptors is independent of PKG. Nat Neurosci 3:559-565.

Lev-Ram V, Nebyelul Z, Ellisman MH, Huang PL, Tsien RY (1997) Absence of cerebellar long-term depression in mice lacking neuronal nitric oxide synthase. Learn Mem 4:169-177.

Linden DC, Guillery RW, Cucchiaro J (1981) The dorsal lateral geniculate nucleus of the normal ferret and its postnatal development. J Comp Neurol 203:189-211.

Lu YF, Kandel ER, Hawkins RD (1999) Nitric oxide signaling contributes to late-phase LTP and CREB phosphorylation in the hippocampus. J Neurosci 19:10250-10261.

Lum-Ragan JT, Gribkoff VK (1993) The sensitivity of hippocampal long-term potentiation to nitric oxide synthase inhibitors is dependent upon the pattern of conditioning stimulation. Neuroscience 57:973-983.

MacMillan-Crow LA, Lincoln TM (1994) High-affinity binding and lo- calization of the cyclic GMP-dependent protein kinase with the intermediate filament protein vimentin. Biochemistry 33:8035-8043.

Meister M, Wong RO, Baylor DA, Shatz CJ (1991) Synchronous bursts of action potentials in ganglion cells of the developing mammalian retina. Science 252:939-943.

Montague PR, Gancayco CD, Winn MJ, Marchase RB, Friedlander MJ (1994) Role of NO production in NMDA receptor-mediated neurotransmitter release in cerebral cortex. Science 263:973-977.

Penn AA, Riquelme PA, Feller MB, Shatz CJ (1998) Competition in retinogeniculate patterning driven by spontaneous activity. Science 279:2108-2112.

Rocha M, Sur M (1995) Rapid acquisition of dendritic spines by visual thalamic neurons after blockade of $N$-methyl-D-aspartate receptors. Proc Natl Acad Sci USA 92:8026-8030.

Schuman EM, Madison DV (1991) A requirement for the intercellular messenger nitric oxide in long-term potentiation. Science 254:15031506.

Schuman EM, Meffert MK, Schulman H, Madison DV (1994) An ADPribosyltransferase as a potential target for nitric oxide action in hippocampal long-term potentiation. Proc Natl Acad Sci USA 91:1195811962.

Sequeira SM, Carvalho AP, Carvalho CM (1999) Both protein kinase G dependent and independent mechanisms are involved in the modulation of glutamate release by nitric oxide in rat hippocampal nerve terminals. Neurosci Lett 261:29-32.

Shatz CJ, Stryker MP (1988) Prenatal tetrodotoxin infusion blocks segregation of retinogeniculate afferents. Science 242:87-89.

Shibuki K, Okada D (1991) Endogenous nitric oxide release required for long-term synaptic depression in the cerebellum. Nature 349:326-328.

Smetters DK, Hahm J, Sur M (1994) An N-methyl-D-aspartate receptor antagonist does not prevent eye-specific segregation in the ferret retinogeniculate pathway. Brain Res 658:168-178.

Son H, Hawkins RD, Martin K, Kiebler M, Huang PL, Fishman MC, Kandel ER (1996) Long-term potentiation is reduced in mice that are doubly mutant in endothelial and neuronal nitric oxide synthase. Cell 87:1015-1023.

Son H, Lu YF, Zhuo M, Arancio O, Kandel ER, Hawkins RD (1998) The specific role of cGMP in hippocampal LTP. Learn Mem 5:231-245.

Song H, Ming G, He Z, Lehmann M, McKerracher L, Tessier-Lavigne M, Poo M (1998) Conversion of neuronal growth cone responses from repulsion to attraction by cyclic nucleotides. Science $281: 1515-1518$.

Song HJ, Ming GL, Poo MM (1997) cAMP-induced switching in turning direction of nerve growth cones. Nature 388:275-279.

Sretavan DW, Shatz CJ, Stryker MP (1988) Modification of retinal ganglion cell axon morphology by prenatal infusion of tetrodotoxin. Nature 336:468-471.

Stryker MP, Zahs KR (1983) On and off sublaminae in the lateral geniculate nucleus of the ferret. J Neurosci 3:1943-1951.

Suhasini M, Li H, Lohmann SM, Boss GR, Pilz RB (1998) Cyclic-GMPdependent protein kinase inhibits the Ras/mitogen-activated protein kinase pathway. Mol Cell Biol 18:6983-6994.

Van Wagenen S, Rehder V (1999) Regulation of neuronal growth cone filopodia by nitric oxide. J Neurobiol 39:168-185.

Vercelli A, Garbossa D, Biasiol S, Repici M, Jhaveri S (2000) NOS inhibition during postnatal development leads to increased ipsilateral retinocollicular and retinogeniculate projections in rats. Eur J Neurosci 12:473-490.

Wakatsuki H, Gomi H, Kudoh M, Kimura S, Takahashi K, Takeda M, Shibuki K (1998) Layer-specific NO dependence of long-term potentiation and biased $\mathrm{NO}$ release in layer $\mathrm{V}$ in the rat auditory cortex. J Physiol (Lond) 513:71-81.

Wang X, Robinson PJ (1997) Cyclic GMP-dependent protein kinase and cellular signaling in the nervous system. J Neurochem 68:443-456.

Wilson RI, Godecke A, Brown RE, Schrader J, Haas HL (1999) Mice deficient in endothelial nitric oxide synthase exhibit a selective deficit in hippocampal long-term potentiation. Neuroscience 90:1157-1165.

Wong RO, Chernjavsky A, Smith SJ, Shatz CJ (1995) Early functional neural networks in the developing retina. Nature 374:716-718.

Wu HH, Williams CV, McLoon SC (1994) Involvement of nitric oxide in the elimination of a transient retinotectal projection in development. Science 265:1593-1596.

Wu J, Wang Y, Rowan MJ, Anwyl R (1997) Evidence for involvement of the neuronal isoform of nitric oxide synthase during induction of long-term potentiation and long-term depression in the rat dentate gyrus in vitro. Neuroscience 78:393-398.

Wu J, Wang Y, Rowan MJ, Anwyl R (1998) Evidence for involvement of the cGMP-protein kinase $\mathrm{G}$ signaling system in the induction of longterm depression, but not long-term potentiation, in the dentate gyrus in vitro. J Neurosci 18:3589-3596.

Zhuo M, Hu Y, Schultz C, Kandel ER, Hawkins RD (1994) Role of guanylyl cyclase and cGMP-dependent protein kinase in long-term potentiation. Nature 368:635-639. 